\section{Age variations in intraocular pressure in a cohort of healthy Austrian school children}

WA Dusek, BK Pierscionek and JF McClelland

\begin{abstract}
Purpose Limited data exist detailing the normal range of intraocular pressure (IOP) for healthy school age children. This study aims to describe the mean and normal range of IOP measurements that may be expected using the Icare rebound tonometer and to examine associations between visual function measures and IOP.

Methods Six measurements of IOP from each eye were obtained from 211 normal children aged 6-15 years (79 females and 132 males) using the Icare tonometer. Other measures of visual function obtained included: visual acuity, non-cycloplegic retinoscopy, amplitude of accommodation, accommodative facility, and accommodative response.
\end{abstract}

Results Statistical analysis (Mann-Whitney $U$ test) demonstrated that the male subjects were more likely to have higher IOP measurements than the female subjects (mean IOP males $15.02 \mathrm{~mm} \mathrm{Hg}$ (SD 2.19), mean IOP females 14.44 (SD 2.01) $P=0.041$ ). Analysis (Spearman's rho) showed a statistically significant association between age and IOP (right eye) in males $(P<0.001)$ but no association for females $(P=0.459)$. Using Spearman's rank analysis, statistically significant associations were found between IOP and amplitude of accommodation in males, for the whole data set $(P=0.09)$ and for data up to age $11(P<0.001)$. For females no statistically significant association was found for the whole data set $(P=0.253)$ or for data up to age $11(P=0.08)$. IOP was not significantly associated with visual acuity, refractive error, accommodative facility, or accommodative response.

Conclusion This study provides useful normative IOP data using the Icare tonometer for a European cohort of school age children.
Eye (2012) 26, 841-845; doi:10.1038/eye.2012.54; published online 23 March 2012

Keywords: intraocular pressure; children; tonometry; Icare

\section{Introduction}

The assessment of intraocular pressure (IOP) using an accurate and reliable technique is essential in the diagnosis and management of congenital and paediatric glaucoma. ${ }^{1}$ The effectiveness of a measure used in detection depends to a large extent on its reliability as a differentiator between normal and abnormal states. When dealing with young children, whose eyes are still experiencing growth and concomitant optical and neural changes, the measurement of IOP for early glaucoma detection is limited by a paucity of data for the normal-growing eye from a number of different populations. There is also uncertainty about methods of measurement, their reliability and effectiveness on the eyes of children. The most trusted method of measurement of IOP for the adult eye was considered to be the Goldmann applanation tonometer. ${ }^{2}$ However, it has been acknowledged to provide no more than an estimate of $\mathrm{IOP}^{3}$ and recent work has questioned the reliability of the correction factor that is applied to adjust for the effect of corneal thickness on the IOP measurement. ${ }^{4}$ Given that corneal thickness affects the measure of IOP to differing extents depending on the instrument used when applied to the adult eye, ${ }^{3}$ the uncertainty is exacerbated when considering the growing eyes of children.

The Goldmann tonometer can be difficult to use on children and correction factors are not known. The Icare tonometer is a dynamic or rebound tonometer that was introduced in
Vision Science Research Group, School of Biomedical Sciences, University of Ulster, County Londonderry, UK

Correspondence: JF McClelland, Vision Science Research Group, School of Biomedical Sciences, University of Ulster, County Londonderry BT52 1SA, UK

Tel: + $44(0) 287012$ 4216; Fax: $+44(0) 2870124965$ E-mail: jf.mcclelland@ ulster.ac.uk

Received: 25 August 2011 Accepted in revised form: 22 February 2012 Published online: 23 March 2012 
$2000 .^{5}$ It is based on the use of a solenoid to launch a magnetised probe against the eye. ${ }^{6}$ It is easy to use, does not require anaesthesia, and is well tolerated by patients including children, making it an ideal tool for primary eye care practice. ${ }^{7,8}$ The Icare tonometer has previously been shown to provide valid and repeatable measures of IOP in children and adults., ${ }^{7-14}$ Similar to other applanation tonometers, the Icare tonometer is influenced by the changes in corneal thickness. ${ }^{15}$ Nakamura et al ${ }^{15}$ reported that the Icare tonometer overestimated IOP in comparison with the Goldmann applanation tonometer, when corneal thickness increased.

Relatively few studies have investigated normal ranges of IOP for infants and children. ${ }^{16-18}$ Pensiero et al ${ }^{18}$ measured IOP using the Pulsair non-contact tonometer in 460 subjects from birth to 16 years and reported a phase of rapid increase in IOP thereafter followed by a stabilisation of values. The age at which the steady phase was reached, however, varied significantly between the genders: males reached the steady phase before females. The reasons for this are not clear and the results are not known to be linked to any variations in growth and development of the eye or to any functional measures or manifestations of visual function. It is notable that IOP shows the greatest variations over the first decade of life when the greatest changes in the optics of the eye and the process of emmetropisation take place.

The present study presents results of IOP measurements, taken with an Icare tonometer, from a cohort of healthy Austrian school children. Age, gender, and relationship to other measures of visual function are explored.

\section{Materials and methods}

Subjects were 211 children aged 6-15 years (79 females and 132 males) attending for a routine eye examination. Subjects with ocular pathology were excluded from the study. Four subjects who presented with a mean IOP over $21 \mathrm{~mm} \mathrm{Hg}$ in at least one eye were referred to an ophthalmologist for further investigation. In all four subjects ophthalmological examination confirmed that no pathology or abnormalities were present so data from these subjects were included in the analysis. All children in the present study were attending mainstream schools.

Before measurements of IOP were obtained, a new sterile disposable probe was inserted into the Icare tonometer. Subjects were asked to relax while the forehead support was adjusted and positioned correctly, and were then advised to fixate a distant target while the measurements were being taken. Six measurements were obtained and an average value calculated. In cases where an error sign was displayed on the Icare tonometer, indicating a larger than acceptable standard deviation, the six measurements were repeated.

Visual acuity was assessed at $5 \mathrm{~m}$ using the Polatest (Carl Zeiss Vision, Oberkochen, Germany), a commonly used European test chart. ${ }^{19,20}$ The refractive error was assessed using distant static retinoscopy and the amplitude of accommodation was measured for each eye using a standard push-up test. ${ }^{21-23}$ Accommodative facility was assessed in cycles per minute both monocularly and binocularly using flipper lenses $(+2.00 /-2.00){ }^{24}$ Monocular estimation method retinoscopy was used to assess accommodative lag to a target at $40 \mathrm{~cm} .^{25}$

All applicable institutional and governmental regulations concerning the ethical use of human volunteers were followed during this research. Ethical approval for the study was obtained from the University of Ulster Research Ethics Committee and the study adhered to the tenets of the Declaration of Helsinki. Fully informed written consent was obtained from the parents of the children participating in the study and verbal assent obtained from the children.

\section{Statistical analysis}

Data were entered into SPSS version 17.0 (SPSS Inc., Chicago, IL, USA), which was used for subsequent analysis. A one sample Kolmogorov-Smirnov test demonstrated that IOP data were not normally distributed. Non-parametric statistical tests were therefore applied and statistical significance was taken to be at the $5 \%$ level $(P<0.05)$.

\section{Results}

Measurements of IOP from both eyes of 211 subjects were subjected to analysis using a Mann-Whitney $U$ test. This did not find any statistically significant difference between the right and left eyes $(P=0.248)$. Therefore, data from a single representative eye per subject (right eye) were used for the analysis.

\section{Age and gender}

Mean IOP values for the right eye in each age group, from male and female subjects, were plotted against age in Figure 1. There is a clear increase in IOP for both the gender groups from 6 to 9 years of age. Thereafter no clear trends are evident, although two observations can be made: (a) notwithstanding the fact that numbers are not large, in both male and female subjects, the IOP decrease by around $2 \mathrm{~mm} \mathrm{Hg}$ at age 11 years; (b) for age group 13-15 years, the IOP values for males are about 2-3 mm Hg higher than that for females. Statistical analysis (Mann-Whitney $U$ test) demonstrated that male subjects were more likely to have higher IOP 
measurements than female subjects (mean IOP males $15.02 \mathrm{~mm} \mathrm{Hg}$ (SD 2.19), mean IOP females 14.44 (SD 2.01) $P=0.041$ ). Analysis using Spearman's rho (one-tailed) showed a statistically significant association between age and IOP (right eye) in all subjects together $(P=0.002)$ and in males only $(P<0.001)$, but showed no association for females $(P=0.459)$. Given that the clearest trend with age occurred in the first decade, analysis of data up to age 11 years only also showed highly significant associations between IOP and age in both males and females $(P<0.001)$ (Table 1).

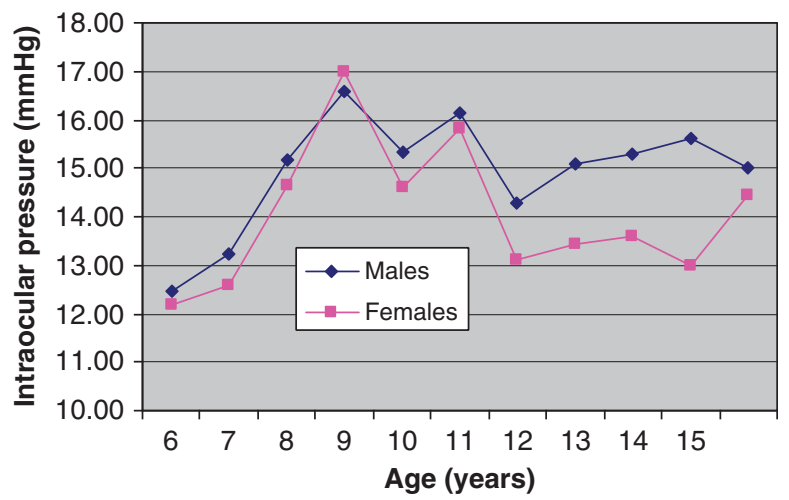

Figure 1 Intraocular pressure measurements for all subjects (RE and LE).

Table 1 Association between IOP and age (Spearman's rho, one tailed) for male and female groups, aged 6-15 years and aged 6-11 years

\begin{tabular}{lcrlccc}
\hline & \multicolumn{2}{c}{ Age (6-15 years) } & & \multicolumn{2}{c}{ Age (6-11 years) } \\
\cline { 2 - 3 } & Spearman's rho & $\mathrm{P}$ & & Spearman's rho & $\mathrm{P}$ \\
\hline Males & 0.317 & $<0.001$ & & 0.484 & $<0.001$ \\
Females & 0.012 & 0.459 & & 0.529 & $<0.001$ \\
\hline
\end{tabular}

Abbreviation: IOP, intraocular pressure.
Normal ranges of IOP (mean $\pm 1.96 \mathrm{SD})$ are presented for each age group category (Table 2).

\section{Visual functions}

Consistent with physiological norms, the amplitude of accommodation decreased steadily with age for both males and females, with males showing consistently higher amplitudes of accommodation than females. Using Spearman's rank analysis, no statistically significant associations were found between IOP and amplitude of accommodation, for the whole data set $(P=0.056)$ or for female subjects only $(P=0.506)$.

However, there was a significant association between IOP and amplitude of accommodation for male subjects $(P=0.018)$ and for all subjects up to age 11 years $(P=0.001)$ (Table 3$)$. Spherical refractive error ranged from -7.00 to $+8.00 \mathrm{D}$ (RE mean + 0.38 D (SD 1.45D), $\mathrm{LE}$ mean $+0.39 \mathrm{D}$ (SD 1.35 D). Cylindrical errors ranged from zero to $-3.25 \mathrm{DC}$ (mean RE -0.14 DC (SD 0.50 DC), mean LE -0.15 DC (SD 0.55 DC)). Refractive error did not show statistically significant variations with age or IOP in all subjects together, males, females or children up to age 11 years (Spearman's rank analysis $P>0.05$ ). No significant associations were found between IOP and

Table 3 Association between IOP and amplitude of accommodation (Spearman's rho, one tailed) for male and female groups, aged 6-15 years and aged 6-11 years

\begin{tabular}{lcclccc}
\hline & \multicolumn{2}{c}{ Age (6-15 years) } & & \multicolumn{2}{c}{ Age (6-11 years) } \\
\cline { 2 - 3 } & Spearman's rho & $\mathrm{P}$ & & Spearman's rho & $\mathrm{P}$ \\
\hline Males & -0.206 & 0.09 & & -0.342 & 0.000 \\
Females & -0.76 & 0.253 & & -0.188 & 0.080 \\
\hline
\end{tabular}

Abbreviation: IOP, intraocular pressure.

Table 2 Mean and normal range of IOP for each age group and gender

\begin{tabular}{lcccccc}
\hline Age (years) & \multicolumn{2}{c}{ Males } & & \multicolumn{2}{c}{ Females } \\
\cline { 2 - 5 } & $\mathrm{n}$ & $\begin{array}{c}\text { Mean IOP } \\
(\mathrm{mm} \mathrm{Hg})\end{array}$ & $\begin{array}{c}\text { Normal range } \\
(\mathrm{mm} \mathrm{Hg})\end{array}$ & $\mathrm{n}$ & $\begin{array}{c}\text { Mean IOP } \\
(\mathrm{mm} \mathrm{Hg})\end{array}$ & $\begin{array}{c}\text { Normal range } \\
(\mathrm{mm} \mathrm{Hg})\end{array}$ \\
\hline 6 & 9 & 12.44 & $8.51-16.37$ & 5 & 12.20 & $10.56-13.84$ \\
7 & 16 & 13.25 & $10.82-15.68$ & 5 & 12.60 & $11.53-13.67$ \\
8 & 32 & 15.16 & $12.05-18.27$ & 14 & 14.64 & $11.33-17.96$ \\
9 & 15 & 16.60 & $12.42-20.78$ & 8 & 17.00 & $13.86-20.14$ \\
10 & 12 & 15.33 & $11.47-19.19$ & 10 & 14.60 & $12.49-16.71$ \\
11 & 13 & 16.15 & $10.73-21.57$ & 15 & 15.80 & $11.79-19.80$ \\
12 & 7 & 14.29 & $10.76-17.81$ & 8 & 13.13 & $10.47-15.78$ \\
13 & 10 & 15.10 & $9.52-20.68$ & 7 & 13.43 & $10.69-16.17$ \\
14 & 7 & 15.29 & $12.58-17.99$ & 5 & 13.60 & $11.85-15.35$ \\
15 & 11 & 16.64 & $13.12-18.16$ & 2 & 13.00 & $7.46-18.54$ \\
\hline
\end{tabular}

Abbreviation: IOP, intraocular pressure. 
visual acuity, accommodative facility or accommodative response (monocular estimate method retinoscopy) (Spearman's correlation $P>0.05$ ).

\section{Discussion}

The present study describes IOP measurements from a large group of healthy Austrian school age children using the Icare tonometer. Chan $\mathrm{et}^{\mathrm{al}} \mathrm{l}^{8}$ highlight the importance of alternative methods of assessment for IOP in children when the Goldmann tonometer is not appropriate. The mean IOP value of $14.80 \pm 2.14 \mathrm{~mm} \mathrm{Hg}$ concurs with those obtained by Youn $e t a l^{26}$

$(13.31 \pm 1.79 \mathrm{~mm} \mathrm{Hg})$ in a study of 527 - to 15 -year-old children. Sihota et al ${ }^{27}$ demonstrated a mean IOP $(12.02 \pm 3.74 \mathrm{~mm} \mathrm{Hg})$ in a group of 405 subjects (0-12 years of age). Differences between these results and the present study may be attributed to the younger participants included in Shiota et al's work. ${ }^{27}$ Jaafar and $\mathrm{Kazi}^{28}$ found significantly lower mean IOP values using the Perkins applanation tonometer $(5.89 \mathrm{~mm} \mathrm{Hg})$ in a group of 50 young children below the age of 5 years. These data represented a very young age group and measurements were taken while subjects were in a supine position.

Mean IOP in each age group significantly increased with increasing age in the present study. Youn $e t a^{26}$ demonstrated a similar trend showing the mean IOP was $11.85 \pm 1.35 \mathrm{~mm} \mathrm{Hg}$ in 10 children under the age of 2 years, $12.80 \pm 1.73 \mathrm{~mm} \mathrm{Hg}$ in 79 children from 2 to 7 years and $13.31 \pm 1.79 \mathrm{~mm} \mathrm{Hg}$ in 52 children from 7 to 15 years. This previous study also showed an increase in variability of IOP with increasing age. ${ }^{26}$ The normal range of IOP in the present study did not increase in width with age.

Pensiero $e t a l^{18}$ measured IOP in 460 subjects over an age range from newborn to 16 years and reported a steady phase in IOP values after 4 years of age in males and after 9 years of age in females. This has to be considered in the context of the age group studied and the finding that very rapid increases occur in the early post-natal years. Any subsequent changes therefore will not be as great and will appear as a relatively stable or plateau phase. Pensiero $e t a l^{18}$ also noted significant differences between the two eyes, greater than that found in this study, and concluded that $2 \mathrm{~mm} \mathrm{Hg}$ difference between the eyes is 'physiologic'. A difference of up to $2 \mathrm{~mm} \mathrm{Hg}$ may also represent variations during ocular pulsations..$^{29}$ If this is taken as indicating a baseline variation or tolerance, it may suggest that any differences below $2 \mathrm{~mm} \mathrm{Hg}$ should not be treated as meaningful. Further work on variations between the eyes and what this may indicate is necessary.
The developing eye experiences a number of changes that lead to adjustment of its optical components in accordance with the natural trend to emmetropise and the sometimes conflicting intervention of environmental influences. While it is well established that central corneal thickness affects IOP measurements, it is not implausible that other physical factors that influence the optics of the eye, refractive status, and other measures of visual function may concurrently affect the measure of IOP. This should be most noticeable in a population of children, the growing eyes of which may show agerelated variations in IOP as well as in other optical parameters, and may hence reveal correlations between IOP and these parameters. In this study, statistically significant associations were found between IOP and age, and these were particularly strong in males; the significance was only evident in females for data up to age 11, the range over which the clearest trends with age were seen (Figure 1). IOP was also found to be associated with amplitude of accommodation but only in males. The association for females became stronger with data up to age 11 , but was significant only at $P=0.08$. As the amplitude of accommodation is known to decrease with age and the IOP was shown to rise in the first decade of life, such an association is not surprising. The fact that males and females vary in significance of associations between IOP and amplitude of accommodation may result from the differences in the IOP changes with age and the deviation of the trends after 12 years of age (Figure 1). Differences between males and females have been noted by Pensiero $e t a l^{18}$ but the greatest deviations were noted before the age of 6 in the previous study.

The present study demonstrated no associations between refractive error and IOP measures. This is in contrast to work by Sihota et $a l^{26}$ who demonstrated a significant association between IOP and refraction. The mean age of subjects in Sihota et al's study were 6.68 ( \pm 3.28$)$ years compared with $10.03 \pm 2.33$ years in this work. Sihota et al included subjects from birth to 12 year of age and demonstrated a mean refractive error of $-1.81 \mathrm{D}$ in the right eye and 1.26 $\mathrm{D}$ in the left eye. The lower mean refractive error in the present study may account for these differences.

Central corneal thickness is known to increase with age in children and may have resulted in the increased IOP in older children in the present study, however, these data were not available from the present study. ${ }^{30}$ Further investigation with the inclusion of corneal thickness data may confirm this theory.

This study adds to the current IOP data on the growing normal eye and is the first such study on an Austrian cohort of school children. Further studies on ocular measures in the first decade of life, from a wide range of populations, are needed to help establish normative 
IOP data and to probe potential associations between clinical measures and visual functions in the growing eye. Differences between the genders and how these may impact on measures and manifest on function also require explanation.

\section{Summary}

\section{What was known before}

- The Icare tonometer provides valid repeatable measures of intraocular pressure in children.

\section{What this study adds}

- Normative data for the Icare tonometer in children. Demonstrations associations between age and intraocular pressure in childhood. Demonstrates no associations between intraocular pressure and refractive or visual parameters in childhood.

\section{Conflict of interest}

The authors declare no conflict of interest.

\section{References}

1 Biglan AW. Glaucoma in children: are we making progress? JAAPOS 2006; 10: 7-21.

2 Carbonaro F, Andrew T, Mackey DA, Spector TD, Hammond CJ. Comparison of three methods of intraocular pressure measurement and their relation to central corneal thickness. Eye 2010; 24: 1165-1170.

3 Bhan A, Brown AC, Shah S, Hamilton R, Dave D, Dua HS. Effect of corneal thickness on intraocular pressure measurements with the pneumotonometer, Goldmann applantion tonometer, and Tono-Pen. Invest Ophthalmol Vis Sci 2002; 43: 1389-1392.

4 Gunvant P, Newcomb RD, Kirstein EM, Malinovsky VE, Madonna RJ, Meetz RE. Measuring accurate IOPs: does correction factor help or hurt? Clin Ophthalmol 2010; 4: 611-616.

5 Kontiola AL. A new induction-based impact method for measuring intraocular pressure. Acta Ophthalmol Scand 2000; 78: $142-145$.

6 Fernandes P, Díaz-Rey JA, Queirós A, Gonzalez-Meijome $\mathrm{JM}$, Jorge J. Comparison of the ICare $\AA$ rebound tonometer with the Goldmann tonometer in a normal population. Ophthalmic Physiol Opt 2005; 25: 436-440.

7 Lundvall A, Svedberg H, Chen E. Application of the ICare rebound tonometer in healthy infants. J Glaucoma 2011; 20: 7-9.

8 Chan WH, Lloyd IC, Ashworth JL, May K, Bhojwani D, Biswas S. Measurement of intraocular pressure in children in the UK. Eye 2011; 25: 119-120.

9 Kageyama M, Hirooka K, Baba T, Shiraga F. Comparison of ICare rebound tonometer with noncontact tonometer in healthy children. J Glaucoma 2011; 20: 63-66.

10 Pakrou N, Gray T, Mills R, Landers J, Craig J. Clinical comparison of the Icare tonometer and Goldmann applanation tonometry. J Glaucoma 2008; 17: 43-47.

11 Jorge J, Fernandes P, Queirós A, Ribeiro P, Garcês C, Gonzalez-Meijome JM. Comparison of the IOPen and iCare rebound tonometers with the Goldmann tonometer in a normal population. Ophthalmic Physiol Opt 2010; 30: 108-112.

12 Asrani S, Chatterjee A, Wallace DK, Santiago-Turla C, Stinnett $\mathrm{S}$. Evaluation of the ICare rebound tonometer as a home intraocular pressure monitoring device. J Glaucoma 2011; 20(2): 74-79.

13 Abraham LM, Epasinghe NCR, Selva D, Casson R. Comparison of the ICare ${ }^{\mathbb{R}}$ rebound tonometer with the Goldmann applanation tonometer by experienced and inexperienced tonometrists. Eye 2008; 22: 503-506.

14 Sahin A, Basmak H, Niyaz L, Yildirim N. Reproducibility and tolerability of the ICare rebound tonometer in school children. J Glaucoma 2007; 16: 185-188.

15 Nakamura M, Darhad U, Tatsumi Y, Fujioka M, Kusuhara A, Maeda $\mathrm{H}$ et al. Agreement of rebound tonometer in measuring intraocular pressure with three types of applanation tonometers. Am J Ophthalmol 2006; 142: 332-334.

16 Richter S, Horn D, Bergknoff H. A survey of intraocular pressures with emphasis on patients under ten years of age. Am J Optom Physiol Opt 1979; 56: 193-196.

17 Duckman RH, Fitzgerald DE. Evaluation of intraocular pressure in a paediatric population. Optom Vis Sci 1992; 69: 705-709.

18 Pensiero S, Da Pozzo S, Perissutti P, Cavallini GM, Guerra R. Normal intraocular pressure in children. J Ped Ophthalmol Strabismus 1992; 29: 79-84.

19 Bauman HE. Use of the polatest in practice. Ophthalmologica 1969; 158: 612-621.

20 Brautaset RL, Jennings JA. Associated phoria and the measuring and correcting methodology after H-J. Haase (MKH). Strabismus 2001; 9: 165-176.

21 Goss DA. Clinical accommodation testing. Curr Opin Ophthalmol 1992; 31: 78-82.

22 Rutstein RP, Fuhr PD, Swiatocha J. Comparing the amplitude of accommodation determined objectively and subjectively. Optom Vis Sci 1993; 70: 496-500.

23 Chen AH, O'Leary DJ, Howell ER. Near visual function in young children. Part I: near point of convergence. Part II: amplitude of accommodation. Part III: near heterophoria. Ophthalmic Physiol Opt 2000; 20: 185-198.

24 Zellers JA, Alpert TL, Rouse MW. A review of the literature and a normative study of accommodative facility. J Am Optom Assoc 1984; 55: 31-37.

25 Locke LC, Somers W. A comparison study of dynamic retinoscopy techniques. Optom Vis Sci 1989; 66: 540-544.

26 Youn DH, Yu YS, Park IW. Intraocular pressure and axial length in children. Korean J Ophthalmol 1990; 4: 26-29.

27 Sihota R, Tuli D, Dada T, Gupta V, Sachdeva MM. Distribution and determinants of intraocular pressure in a normal pediatric population. J Pediatr Ophthalmol Strabismus 2006; 43: 14-18.

28 Jaafar MS, Kazi GA. Normal intraocular pressure in children: a comparative study of the Perkins applanation tonometer and the pneumatonometer. J Pediatr Ophthalmol Strabismus 1993; 30: 284-287.

29 Schacknow PN, Samples JN. The Glaucoma Book: A Practical, Evidence-Based Approach to Patient Care. 1st edn. Springer-Verlag Press: New York, 2010.

30 Pediatric Eye Disease Investigator GroupBradfield YS, Melia BM, Repka MX, Kaminski BM, Davitt BV, Johnson DA et al. Central corneal thickness in children. Arch Ophthalmol 2011; 129: 1132-1138. 